\title{
A RESPONSABILIDADE SOCIAL DA EMPRESA E A CIDADANIA NA PARTICIPAÇÃO DEMOCRÁTICA
}

\section{THE COMPANY'S SOCIAL RESPONSIBILITY AND THE CITIZENSHIP IN DEMOCRATIC PARTICIPATION}

\section{LEANDRO SOUZA ROSA}

Mestrando em Direito Empresarial e Cidadania pelo Centro Universitário Curitiba. Especialista em Direito e Processo Penal pela Universidade Estadual de Londrina. Especialista em Direito Administrativo pelo Instituto de Direito Romeu Felipe Bacellar. Graduado em Direito pela Universidade Estadual de Londrina. Vice-Presidente da Comissão De Direito Eleitoral da Ordem dos Advogados do Brasil - Seção do Paraná. Membro fundador do Instituto Paranaense de Direito Eleitoral - IPRADE. Membro fundador da Academia Brasileira de Direito Eleitoral e Político - ABRADEP. Advogado e Consultor na área do Direito Eleitoral e Partidário.

\section{RESUMO}

Este artigo analisa a responsabilidade social e ética da empresa, que não se limita a gerar empregos e pagar impostos para criar o lucro, mas também participa ativamente da sociedade, já que o Estado possui uma demanda maior do que consegue suprir e as empresas podem desempenhar o papel de agentes de grandes transformações na vida dos indivíduos. Para tanto, examinou-se a concepção da função social no Estado Democrático de Direito, bem como o instituto da responsabilidade social, cujas diretrizes baseiam-se na cidadania por meio da participação democrática, de modo que 0 modelo que melhor se enquadraria nesse sistema é 0 da democracia deliberativa, conforme se demonstra. Assim, por meio de exemplos concretos, buscou-se demonstrar que a empresa pode desenvolver a participação democrática para se envolver no processo decisório e fomentar a evolução social. 
PALAVRAS-CHAVE: Empresa; Responsabilidade Social; Cidadania; Democracia.

\section{ABSTRACT}

This article analyzes the social and ethical responsibility of the company, which not only generates jobs and pay taxes to create profit, but also actively participates in society, since the State has a greater demand than it can supply and companies can play the role of agents of great transformations in the life of individuals. For this, the conception of the social function in the Democratic State of Law, as well as the institute of social responsibility, whose guidelines are based on citizenship through democratic participation, was examined, so that the model that would fit best in this system is that of deliberative democracy, as demonstrated. Thus, through concrete examples, it was tried to demonstrate that the company can develop the democratic participation to be involved in the decision-making process and to foment the social evolution.

KEYWORDS: Company; Social Responsibility; Citizenship; Democracy.

\section{INTRODUÇÃO}

O presente estudo analisa a empresa e suas transformações com o decorrer do tempo, bem como sua postura constitucional em relação à responsabilidade social e ética, que não se limita à geração de empregos e pagamento de impostos para calcular o lucro, vez que pode avançar para a participação ativa na sociedade, na medida em que o Estado possui demanda maior do que pode suprir, enquanto que as empresas são agentes de grandes transformações na vida dos indivíduos.

O exame do tema perpassa pelo exposto na Constituição Federal sobre a referida responsabilidade, explicando o que significa a função social no Estado Democrático De Direito, cuja base reside na função social da própria propriedade, que é dinamizada para o sentido da livre iniciativa econômica, visando a atuação em prol da coletividade. Segue, a abordagem, no aprofundamento da responsabilidade social 
da empresa em si, refletindo sobre sua construção e consolidação, bem como a sua necessidade, o que conduziu o trabalho para o estudo da cidadania na participação democrática.

Esse referido tópico tratou de aspectos fundamentais da sociedade, com pontos aplicáveis à temática empresarial, para chegar ao conteúdo da democracia deliberativa como o entrelace da democracia representativa e participativa. Nesse aspecto, foi crucial a demonstração da importância da participação social nas decisões tomadas, sejam elas políticas, administrativas ou jurídicas, de modo que a deliberação abre espaço para que a voz dos cidadãos e das empresas seja ouvida.

Por fim, enfatizou-se políticas estruturantes que evidenciam a responsabilidade social das empresas, para o que foi desenvolvida uma análise normativa do assunto, visto que não há obrigação legal consolidada no ordenamento jurídico que oriente e obrigue as empresas a agirem dessa forma. Após, foi empreendida análise histórica para a compreensão da atual conceituação do instituto, bem como foram apresentadas exemplificações concretas da responsabilidade social das empresas em exercício de ambiente democrático, incluindo-se breve análise da empresa social.

No decorrer do trabalho, demonstra-se o comprometimento com o contexto no qual se insere a atividade empresarial, que apresenta importantes reflexos sociais e jurídicos, os quais exercem influência sobre a evolução social, realizada de diversas maneiras, como a preservação do meio ambiente, a promoção social da pessoa, o desenvolvimento de melhores condições para os trabalhadores, a difusão da cultura, a estruturação de políticas públicas, entre outras. Nesse sentido, pretende-se a compreensão da função da empresa na sociedade, e das formas como tal ente pode participar da vida democrática do meio social em que está inserida, enfatizando qual a importância da mesma e seus efeitos, sejam jurídicos ou sociais, de forma a apontar a construção do tema e exemplos que trazem a realidade concreta da teoria. 


\section{A EMPRESA NO CONTEXTO CONSTITUCIONAL}

A Constituição da República Federativa do Brasil de 1988 trouxe importantes inovações, especialmente entre o equilíbrio do Estado Liberal e a ideologia do Estado Social, passando a ser conhecida como Constituição Cidadã (FONSECA, 1995, p. 80), de modo a promover o bem-estar social (LOPES, 2006, p. 33) por meio da preservação da liberdade econômica num contexto de proteção e garantia dos direitos fundamentais.

A atuação que transita entre o campo social e econômico (OLIVEIRA, 2008, p. 03) também insere no ordenamento jurídico uma nova concepção sobre a empresa que, para além da sua função econômica, passa a incumbir-se expressamente da função social. Nessa perspectiva, primeiramente, cabe ressaltar que empresa é "um lugar em que se produz alguma coisa" (ROCHA FILHO, 2004, p. 53) que compõe "fatores com o fim de obter produtos e serviços nas melhores condições de racionalidade econômica de modo que satisfaça as necessidades dos clientes de forma eficiente" (SANTIAGO, 1994, p. 101). Ainda, nesse contexto, o Código Civil de 2002 definiu a concepção de empresário como "quem exerce profissionalmente atividade econômica organizada para a produção ou a circulação de bens ou de serviços" (BRASIL, Código Civil, art. 966).

Sua base constitucional reside no princípio da função social da empresa, um dos princípios fundamentais que consolidam o Estado Democrático De Direito, no qual está inserida a Ordem Econômica, aparato este que sustenta o ordenamento jurídico e "expressa opções políticas fundamentais, configuram eleição de valores éticos e sociais como fundantes de uma ideia de Estado e de Sociedade" (ESPÍNDOLA, 1999, p. 75), de maneira que deve ser interpretada de maneira dinâmica para que possa se adequar às alterações sociais constantes, no intuito de instrumentá-las, o que enseja o desenvolvimento da Ordem Econômica Social, oriunda da aliança entre o viés econômico e o social, sendo o primeiro a base de fomento para o segundo.

A função social encontra disposição nos arts. 5ํ, XXIII e 170, III da CRFB/88 e sua observância contribui para o desenvolvimento econômico, social e cultural da 
Personalidade Acadêmica Homenageada:

Carlos Aurélio Mota de Souza (Universidade Ibirapuera - UNIB)

sociedade (COELHO, 2012, p. 127), seja por meio de geração de empregos, pagamento de tributos, circulação de riquezas ou promoção da sustentabilidade.

A partir disso, é importante examinar o instituto da propriedade, que antes possuía um caráter absoluto e inviolável por estar diretamente ligado à "preservação da liberdade individual" (CARVALHO, 2012, p. 17), mas, com o passar do tempo, veio a adquirir nova roupagem, de modo que seu uso "restringido, com limites e obrigações" (CARVALHO, 2012, p. 18) barra o abuso que ocorria e, consolidado no art. 113, §13 da Constituição Federal de 1934, garante que não seja exercido contra interesse coletivo, formulando paradigma de "dessacralização do direito de propriedade que, de direito fundamental do indivíduo e forma de manifestação de sua liberdade, de caráter eminentemente individual e privado, passou a ser vista sob o paradigma social" (RIBEIRO, 2000, p. 95).

O direito fundamental de propriedade deve respeitar a função social, conformando-se as determinações constitucionais e legais, pois deve "ser exercido de acordo com a Constituição Federal e com as leis ordinárias que conformam o direito de propriedade influenciado pelas ideias de um Estado Social" (FERNANDES, 2008, p. 210). Deste modo, "como vínculo que atribuiu à propriedade conteúdo específico, de sorte a moldar-lhe um novo conceito, que só tem sentido e razão de ser quando referida à propriedade privada" (GRAU, 2005, p. 232), pois, o exercício da empresa privada significa corolário da propriedade privada "porque tem em sua formação o ingresso de capitais originariamente pertencentes a proprietários privados, permitindo que o lucro obtido com sua atividade reverta em prol daquelas pessoas (naturais ou jurídicas) que detém o seu controle" (CAVALLAZZI FILHO, 2007, p. 82).

Nesse sentido, o princípio da função social da empresa segue a mesma linha de raciocínio, apenas enfatizando que significa a propriedade de produção, devendo promover o equilíbrio entre a finalidade de lucro e os interesses da coletividade (CARVALHO, 2012, p. 26), para que a comunidade na qual está inserida tenha suas demandas contempladas. Cabe à empresa cumprir a função social em atendimento à função social da propriedade, por significar a propriedade privada organizada de forma dinâmica, de modo que, na concepção da empresa como conjunto de bens em dinamismo, objeto de um tratamento jurídico diferenciado da propriedade, encontram- 
se as bases "que justificam o entendimento da empresa como detentora de função social, mas também ponderáveis razões a justificar a construção desenvolvida em torno da ideia da empresa como sujeito de direitos" (GRAU, 1981, p. 115).

Ora, "a propriedade em regime de empresa é discernida a partir da consideração da propriedade dinâmica que não tem por objeto a fruição do seu titular - mero direito subjetivo - mas a produção de outros bens - função" (GRAU, 2005, p. 237), de modo que seu exercício deve ser considerado em duas situações: no "momento estático, quando ela é regulada em termos de pertença ou pertinência (...), outro, o momento dinâmico, em que regulada em razão do fim a que socialmente se destina" (GRAU, 2005, p. 244), para que "a empresa como confluência de capital e trabalho, seja instrumento de uma reelaboração do conceito de propriedade" (COSTA, 1956, p. 172).

Tem-se que a empresa dinamiza a propriedade pela livre iniciativa econômica e deve atender à função social em prol da coletividade, consolidando-se como "um dos principais agentes de desenvolvimento da nação" (CAVALLAZZI FILHO, 2007, p. 86). Ainda, sabe-se que a atividade econômica da empresa privada como elemento da Ordem Econômica se submete ao princípio da função social da propriedade, bem como sua própria estrutura somada aos bens de produção constituem a propriedade privada, de modo que o referido princípio não apenas delimita e fiscaliza as atividades da empresa em virtude do interesse público, "mas também, em determinados momentos, como uma garantia que a própria Constituição da República oferece para defender a integridade dos Bens de Produção e das atividades exercidas pela Empresa Privada" (CAVALLAZZI FILHO, 2007, p. 92). A liberdade econômica, princípio constitucional (arts. 1ำ, IV e 170, caput, da CRFB/88), deve ter sua execução baseada no interesse da justiça social "sendo ilegítima quando visar a um puro lucro e realização pessoal do empresário" (SILVA, 2001, p. 772), de modo que é necessário que possua utilidade coletiva para que "não implique barreira capaz de obstar a realização dos objetivos públicos" (MELLO, 2013, p. 834).

Todavia, a função social da empresa não pode tornar a própria atividade da empresa inviável, de maneira a exigir que sua função primordial se baseie no desenvolvimento da sociedade, visto que seu objetivo é o lucro, sem o qual não 


\section{Personalidade Acadêmica Homenageada:}

\section{Carlos Aurélio Mota de Souza (Universidade Ibirapuera - UNIB)}

sobrevive. Mas é com fundamento nesse objetivo que são postas as referidas limitações como requisitos, para evitar abusos e violações de direitos. É claro que deve possuir responsabilidade social e ética, para estruturar a consolidação da evolução social da modernidade. A ética do compromisso com o contexto social e a compreensão de seus efeitos na vida de cada indivíduo inserido no mesmo.

\section{A RESPONSABILIDADE SOCIAL DA EMPRESA}

Considerando o instituto da empresa inserida na ordem constitucional, bem como suas características relacionadas à função social, sabe-se que as práticas de responsabilidade social surgiram do pragmatismo empresarial, de modo que se sustenta por uma ética norteadora de decisões, abordada no tópico anterior, bem como relações com os agentes envolvidos nas trocas econômicas e sociais, constituindo compromisso com a legalidade e as demandas do contexto no qual está inserida para que promova a vida digna aos cidadãos.

Essa responsabilidade propõe a compatibilização da atividade empresarial com os preceitos da Constituição brasileira de $1988^{1}$, de modo que age conforme o ordenamento jurídico - representado pelo Direito no contexto geral, função social da empresa e os princípios, sejam públicos ou privados, objetivando o melhor cenário para o interesse público envolvido (BESSA, 2006, p. 141). Essa responsabilidade deve ser embasada como forma de gestão que se define ética e transparência da empresa para com os públicos que se relaciona, por meio de "metas empresariais que impulsionem o desenvolvimento sustentável da sociedade, preservando recursos ambientais e culturais para as gerações futuras, respeitando a diversidade e promovendo a redução das desigualdades sociais" (ETHOS, 2018).

A responsabilidade visa promover, tanto o bem-estar dos agentes que estão envolvidos, seja com relação ao desenvolvimento do profissional, quanto "proteger os recursos naturais locais; respeitar o direito dos consumidores e os direitos humanos

1 Para análise desse tema, Cf. SILVA, Marcos Alves; KNOERR, Viviane Coelho de Séllos. Responsabilidade social da empresa e subcidadania pautas para uma reflexão de índole constitucional. Revista Jurídica - Unicuritiba. Curitiba: Centro Universitário Curitiba, 2013, vol. 2, n.ำ 31, p. 435-453. 
em geral; enfim, a satisfação de necessidades fundamentais da coletividade" (SOUZA, 2007, p. 50). E, desse modo, tendo em vista a insuficiência do Estado para suprir as demandas sociais modernas, atenta-se ao auxílio das empresas, que também são responsáveis por determinados problemas sociais, de modo que ocasionou a expectativa por ações socialmente responsáveis, por meio de ações cotidianas dos gestores, como exemplifica Mara (DARCANCHY, 2011, p. 34): (i) preocupação com a comunidade local, (ii) tratamento digno dos seus colaboradores por políticas públicas de contratação, (iii) não ter contato profissional com nenhum fornecedor que se utilize de mão de obra infantil, escrava ou outra forma degradante, (iv) cuidado com a sustentabilidade do meio de produção com o meio ambientem (v) pagamento dos impostos devidos e salários justos sem discriminação (DARCANCHY, 2011, p. 34).

O comprometimento com a ética objetiva melhores condições de vida para os agentes incluídos na atividade empresarial por meio da promoção dos valores comunitários concernentes à vida digna, conciliada com a evolução social, significa grande desafio aos envolvidos. Neste sentido, sabe-se que a empresa contemporânea está imersa no contexto econômico com a responsabilidade de atender à função social que "não incide sobre os fins empresariais, como o lucro, mas sobre os meios pelos quais esses fins serão atingidos" (ROSENVALD; FARIAS, 2012, p. 389), de modo que, por meio da empresarialidade responsável, a responsabilidade social é imposta aos empresários e impede que "o intuito lucrativo venha a violar direitos fundamentais da pessoa humana e interesses coletivos", como, por exemplo, coibindo a prática das "vendas casadas", dos cartéis, dos danos ao meio ambiente, e, por outro lado, exigindo a promoção das atividades sociais, justificando a concessão da personalidade jurídica às empresas.

Essa busca pela racionalidade econômica nas atividades fundamenta-se na referida ética empresarial, de modo que não pode violar direitos fundamentais e deve seguir os preceitos constitucionais, especialmente a dignidade da pessoa humana e solidariedade social (ROSENVALD; FARIAS, 2012, p. 390). Da evolução da atividade empresarial, percebem-se as transformações sociais "decorrentes da mutação da empresa, que emergiu como um fator crucial da vida econômica, exercida pelo empresário, sujeito de direito da atividade empresarial” (FERNANDES, 2015, p. VII). 
Portanto, como fomento à geração de riqueza, emprego e consequente desenvolvimento do contexto social, possui função mais ampla que meramente a caça ao lucro, mesmo que este determine a manutenção da atividade produtiva (FERNANDES, 2015, p. VIII), de modo que seu sucesso se afere, tanto dos resultados numéricos, quanto da sua contribuição social - que integra os agentes da produção e constrói uma sociedade de qualidade (SAINSAULIEU; KIRSCHNER, 2006, p. 27). O mercado exige essa qualidade das empresas que, associadas à ética, devem ser observadas, sob pena de responsabilização. Aqui, a ética tem um papel extremamente relevante pois, além de social, deve ser ético, o que significa dizer "agir sempre em conformidade com os valores da honestidade, verdade e justiça, em todas as atividades nas quais representem essas entidades jurídicas" (CARVALHO, 2012, p. 46).

A ética pode ser adotada por meio de imposição ou cooperação, o que difere entre uma metodologia e outra é sua eficiência e duração. Essa tendência consolidouse como uma obrigação jurídica, de modo que se considera que "somente serão duradouras neste século as empresas que souberem criar uma sociedade nova, as organizações empresariais que possam ser reconhecidas como ética, social e ambientalmente responsáveis" (PERAZZO, 2007, p. 152).

Esse alinhamento demonstra a maturidade da relação entre Direito e Economia, com o intuito de ressignificar a valorização das empresas inclusive no mercado, visto que devem possuir os objetivos definidos conforme o ordenamento jurídico. E, para positivar esses valores e sistematizar os princípios gerais da disciplina, é interessante analisar a possibilidade de construção do novo Código Comercial (Projeto de Lei n. 1.572/2011), que proporcionaria a renovação da produção doutrinária e jurisprudencial, com a superação de muitos conceitos velhos, anacrônicos, e arejamento dos que ainda tem operacionalidade (COELHO, 2011, p. 8).

Isso porque se sabe que "normas claras e adequadas, estabelecidas na justa medida da distribuição da proteção dos interesses, têm maior chance de granjearem o respeito dos agentes econômicos e de serem aplicadas pelo Poder Judiciário" (COELHO, 2011, p. 14), já que permitem a mensuração de custos e riscos do 
empresário, entabulando preços competitivos. A empresa exerce papel ímpar na sociedade, de modo que altera e influencia o comportamento dos indivíduos nos mais diversos aspectos: sociais, políticos, jurídicos e econômicos, motivo pelo qual possui o papel de atender as necessidades dos clientes e gerar lucro, mas, além disso, desempenham um papel ainda mais importante, pois a sua influência se estende aos mais variados níveis sociais e ambientais, pois, "além da geração de empregos e movimentação de renda, as empresas contribuem para o desenvolvimento social e ambiental do país" (CARDOSO, 2013, p. 5), ou seja, são agentes sociais modificadores.

A inovação da legislação empresarial brasileira é resultado da competitividade advinda da economia globalizada, que considera a responsabilidade social uma ferramenta estratégica para incrementar os negócios (CARVALHO, 2012, p. 36), não se olvidando da necessidade de se potencializar a consciência de espaço social comunicativo, promovendo a ética ocasionada pela vida em sociedade, que fomenta ações empresariais positivas e a consequente obrigação de preservá-las. As empresas comprometidas com a evolução social devem auxiliar no combate às desigualdades e seus efeitos, de modo que busque ampliar possibilidades de liberdade social, enfatizando a inclusão dos cidadãos.

Como exemplo desse conceito, pode-se citar o instituto da empresa social, de caráter multidimensional, que resulta em negócio empresarial rentável que cria transformações socioambientais por meio de soluções de mercado. Inserida na globalização das relações, as quais são embasadas pelo poder econômico, significa empresa que visa a promover a sociedade e sanar o conflito entre ordem econômica e justiça social. Isto pois, além da atividade econômica, a empresa social possui responsabilidade perante a extensão da sociedade, de modo que deve integrar e liderar a transformação social por meio da interação. Artur Roman (ROMAN, 2004, p. 32) defende que a responsabilidade social deve ser analisada como parte da articulação das forças econômicas que pretendem amenizar os flagelos que elas mesmas criaram. Deste modo, a empresa como agente social objetiva o bem-estar dos cidadãos perante o sistema do mercado por meio da redução dos danos sociais e preservação do meio ambiente, para atingir a sustentabilidade financeira. 
Ainda, convém ressaltar a teoria da juridificação, que significaria a responsabilidade social da empresa não apenas mais como um valor ético, mas sim como um princípio, que seria a expressão da sua validade normativa, o que reforçaria a sua aceitação pela comunidade" (SERRA, 2011, p. 599), ao contrário da visão clássica do Direito constituído em determinado contexto de realidade histórica e social, de maneira que a normatividade jurídica é o sentido do comportamento considerado socialmente adequado. Nesse sentido, Teubner analisa a evolução do sistema jurídico para com a materialização da lei formal, construindo crítica de um novo modelo de direito material que restaria no direito regulatório, no qual o próprio direito assumiria outras funções, pois seria "instrumental, como um mecanismo de regulação ou direção social, em ordem à consecução de determinados objetivos formulados pelo sistema político" (TEUBNER, 1988, p. 46).

Essa compreensão não significa inovação jamais presenciada, visto que Norberto Bobbio já defendia tal entendimento, quando considerou que a função de um ordenamento jurídico não seria somente a de "controlar o comportamento dos indivíduos, o que pode ser obtido por meio da técnica das sanções negativas, mas também direcionar os comportamentos para certos objetivos preestabelecidos" (MARTINS, 2009, p. 17). O direito deve se transformar na medida em que as mudanças da sociedade acontecem, para que sirva de instrumento de direção social, com ênfase na função promocional, e, assim, promover os atos socialmente desejáveis (NETO, 2011, p. 03). Nesse contexto, a responsabilidade social da empresa demanda "técnicas inovadoras, que tornem os comportamentos ou as condutas, os atos ou as práticas, não obrigatórios, mas desejáveis ou apetecíveis aos sujeitos - assim como os atos contrários a elas indesejáveis ou repugnantes" (SERRA, 2011, p. 605). Como uma nova forma de exercício do controle social por condicionamentos psicológicos, agrega, também, técnicas de encorajamento ao promover e favorecer valores e motivar ou estimular comportamentos socialmente desejáveis e responsáveis.

O Direito, portanto, evolui de um estado reativo e atinge um nível de dinamicidade que abandona o seu caráter impositivo e sancionatório assumir uma postura regulatória, sob a responsabilidade da condução de processos e objetivos 
sociais, por meio dos instrumentos normativos submetidos à formulação e implementação das normas. Essa função promocional indica a direção das mudanças sociais por meio do incentivo de valores e comportamentos socialmente desejáveis e responsáveis.

\section{A CIDADANIA NA PARTICIPAÇÃO DEMOCRÁTICA}

Explorada a questão da empresa e da sua responsabilidade social, é preciso agora examinar o contexto moderno em que se inserem as referidas concepções, ou seja, no Estado de Direito, modelo que se vincula à observância de uma pauta de valores entre os quais o princípio da dignidade da pessoa humana e os direitos fundamentais desempenham um papel essencial (NOVAIS, 2012, p. 17).

Por meio da limitação de poder, sua consolidação visa o combate de arbitrariedades e abusos do poder. O modelo do Estado de Direito é responsável por impor limites ao Estado e assegurar as garantias constitucionais aos cidadãos, tendo sido o formato que consolidou a democracia como "um conjunto de regras (primárias ou fundamentais) que estabelecem quem está autorizado a tomar as decisões coletivas e com quais procedimentos" (BOBBIO, 1992, p. 18), de modo a se firmar como princípio informador do Estado e da sociedade e promover a democratização da democracia, para além das fronteiras do território político (CANOTILHO, 1992, p. 421), como um processo dinâmico, "próprio de uma sociedade que aceita o desenvolvimento do cidadão, proporcionando sua participação no processo político em condições de igualdade, o que se reflete no campo econômico, político, social e jurídico" (FERRARI, 2003, p. 331).

Nesse ponto, é necessário ter presente que se atentar apenas para a democracia política pode ocasionar o "esquecimento da democracia administrativa, quando, na verdade, esta deveria ser o reflexo necessário da primeira" (MEDAUAR, 1986, p. 38), problema sanado com a democratização da administração, seja por meio de substituição de estruturas hierárquicas por deliberação colegial, voto na seleção de direção individual, participação paritária dos agentes da Administração Pública, 
transparência do processo administrativo, gestão participada dos cidadãos por organizações (CANOTILHO, 1992, p. 433). Essa participação fomenta-se porque "certos direitos fundamentais adquiririam maior consistência se os próprios cidadãos participassem nas estruturas de decisão" (CANOTILHO, 1992, p. 558), já que para consolidar a eficácia de um direito fundamental, há "a necessidade de a lei criar estruturas organizatórias funcionalmente efectivantes desse direito" (CANOTILHO, 1992, p. 652).

A cidadania, apesar de ser uma ideia amplamente aceita e disseminada, possui certa dificuldade até mesmo quanto à sua noção, pois "os diferentes sujeitos e atores sociais são unânimes na incorporação da palavra cidadania com um valor positivo, no entanto, por detrás desse aparente consenso existe uma pluralidade de enfoques, concepções e questões concretas" (CANDAU, 2008, p. 10). Deste modo, procurando a dimensão da educação voltada para a cidadania, em um contexto desfavorável para política, foi promulgada a Constituição Cidadã.

A Constituição Federal2 construiu "maior participação dos cidadãos na esfera administrativa. Em face disso, teve início no Brasil a real democratização administrativa, a ser implementada por intermédio da participação popular" (OLIVEIRA, 1997, p. 156), por meio do processo no qual se desenham "as regras que há de seguir a formação, a manifestação e a execução da vontade dos órgãos administrativos assegurando-se a participação conveniente e justa dos membros da coletividade" (CAETANO, 1967, p. 32). Assim, no Estado Social vige o princípio da participação popular que objetiva ação democrática na administração da coisa pública (COMPARATO, 1996, p. 19).

Essa ação democrática é exercida por meio da cidadania, que manifesta o vínculo do indivíduo com o Estado como "um círculo de capacidade conferido pelo Estado aos cidadãos" (BONAVIDES, 2003, p. 77), fundamento do ordenamento jurídico brasileiro (art. 1ำ II, Constituição Federal), que busca a inserção da participação popular tanto na tomada de decisões políticas por meio do exercício ativo do poder democrático (FERREIRA FILHO, 2000, p. 19), na perspectiva da relação

${ }^{2}$ Como ocorre no art. 206, VI da Constituição Federal, dispositivo que estabelece um dos princípios constitucionais do ensino: "a gestão democrática do ensino público, na forma da lei" (BRASIL, Constituição Federal, 1988, art. 206) 
Estado-cidadão, de modo que a cidadania, "constitui-se na criação de espaços sociais de luta (movimentos sociais) e na definição de instituições permanentes para a expressão política (partidos, órgãos públicos) significando necessariamente conquista e consolidação social e política" (VIEIRA, 2002, p. 40).

A cidadania moderna advinda com o Estado Social promove a participação como parte principal do processo de desenvolvimento do povo, que deve ser consolidada em cinco pontos: distribuição dos bens indispensáveis à dignidade, proteção dos interesses difusos ou transindividuais, controle do poder político, administração da coisa pública e proteção dos interesses transnacionais (COMPARATO, 1996, p. 10). Nesse sentido, é preciso ressaltar que a cidadania está interligada às ações das empresas - corporações privadas com fins lucrativos -, de modo que a exerce por meio da responsabilidade social e ética, ponderando a importância do seu papel na sociedade. Essas medidas exigem consciência social dos agentes empresários que vão para muito além do seu objetivo econômico, analisadas por longa data, já que, desde os anos 1990, a ideia da "responsabilidade social corporativa" ganhou consistência no meio empresarial e foi compreendida como o complexo de atividades que a empresa realiza, com o objetivo de suprir as "necessidades dos seus empregados e dependentes e, externamente, às demandas das comunidades, em termos de assistência social, alimentação, saúde, educação, preservação do meio ambiente, e desenvolvimento comunitário, entre outras" (CESAR, 2008, p. 18).

Essa responsabilidade, portanto, poderia até ser denominada ou conhecida como "cidadania corporativa", teoria criticada por coadunar com os interesses diretos de lucro, demonstrando determinada ambiguidade entre as condutas cidadãs e o objetivo da empresa. Resta claro que a cidadania compreendida na sua atual concepção, adere à uma mudança drástica da democracia, especialmente refletindo que seu pleito por representação popular não engloba mais apenas a expressão do voto destinado ao candidato e suas respectivas questões de representatividade, mas sim exige técnicas diretas de participação, por meio da "formação da vontade política de 'baixo para cima', num processo de estrutura de decisões com a participação de todos os cidadãos" (CANOTILHO, 1992, p. 413). 


\section{A DEMOCRACIA DELIBERATIVA: 0 ENTRELACE ENTRE A REPRESENTAÇÃO E A PARTICIPAÇÃO}

Nesse sentido, pode-se constatar que, diante das exigências da cidadania moderna, a dominância da democracia representativa não é mais suficiente para suprir as necessidades sociais, de modo que é preciso associá-la à participativa, de modo a conduzir ao "aprimoramento da conduta dos parlamentares ante o paralelismo da atuação popular; e pode-se ponderar que se trata de mais um meio de compatibilizar as decisões estatais às aspirações e reais interesses da coletividade" (MEDAUAR, 2003, p. 233).

Extraem-se da teoria formulada por Boaventura de Sousa Santos ${ }^{3}$ duas soluções: a coexistência da democracia representativa em nível nacional e da participativa em nível local ou a articulação de ambas através da complementaridade - a qual possui o objetivo de "associar ao processo de fortalecimento da democracia local formas de renovação cultural ligadas a uma nova institucionalidade política que recoloca na pauta democrática as questões da pluralidade cultural e da necessidade de inclusão social" (AVRITZER; SANTOS, 2002, p. 76). A complementariedade, ainda, significa "uma decisão da sociedade política de ampliar a participação em nível local através da transferência ou devolução para formas participativas de deliberação de prerrogativas decisórias a princípio detidas pelos governantes" (AVRITZER; SANTOS, 2002, p. 76).

Disso extrai-se, portanto, que a concepção de deliberação pertence aos debates atuais sobre democracia, especialmente pelo seu caráter inovador e pela crise da democracia representativa, diante da insuficiência de efetividade quanto às expectativas dos cidadãos nas sociedades plurais, de modo que a democracia deliberativa visa o alcance da legitimidade do sistema democrático por meio da reformulação teórica. Na procura pela harmonia entre governantes e governados é

\footnotetext{
${ }^{3}$ Nesse sentido, Cf. AVRITZER, Leonardo; SANTOS, Boaventura de Sousa. Introdução: Para Ampliar o Cânone Democrático, 2002.
} 
que a democracia deve se consolidar como forma de governo na qual a soberania popular seja efetiva, o que visa a democracia deliberativa, já que "o processo democrático não pode ser reduzido ao momento decisório; inclui também a possibilidade de se debater acerca dos assuntos a serem decididos; envolve um momento tipicamente deliberativo" (SOUZA NETO, 2006, p. 71), pois é necessária a comunicação dos indivíduos envolvidos no processo decisório (MACHADO, 2015, p. 236).

Neste trabalho é tratada a noção de democracia deliberativa conforme o modelo cooperativo de Carlos Santiago Nino, de modo que, para tanto, é necessário entender que ela significa uma construção do modelo substantivo de Rawls e do modelo procedimental de Habermas. O modelo substantivo parte da concepção de razão pública, de modo que analisa a aplicação dos princípios substantivos de justiça e suas eventuais colisões, por meio do estabelecimento de regras: da prioridade e da liberdade (SOUZA NETO, 2006, p. 102).

O modelo procedimental, por sua vez, buscou o entrelace entre a soberania popular e do Estado de Direito, visando a garantir também a participação das minorias nas decisões políticas (SOUZA NETO, 2006, p. 104), para que não sejam ocasionados danos irreparáveis aos direitos fundamentais das minorias e aos valores sociais decorrentes do processo democrático (SARMENTO, 2007, p. 16), de modo que os cidadãos possam usufruir da cognição sobre as decisões, especialmente pelo Executivo e Judiciário (ZOLO, 2006, p. 37). Nesse sentido, Habermas estuda a compatibilização "da participação com os problemas colocados à sociedade moderna pela complexidade e pelo pluralismo" (FARIA, 2000, p. 48), por meio da "razão comunicativa" (SOUZA, NETO, 2006, p. 136) inclui as preocupações dos cidadãos (FARIA, 2000, p. 58).

Já o modelo cooperativo possui o objetivo de entrelaçar ambas as teorias ora expostas, para equilibrar os elementos. Considera, por um lado, a liberdade basilar para o exercício da soberania popular (SOUZA NETO, 2006, p. 162) no sentido de auferir autonomia às escolhas individuais e, por outro, a igualdade fundamental para a consolidação da justiça, visto que promove a igualdade de responsabilização entre os indivíduos com relação às decisões deliberadas. Como forma efetiva para construir 
os interesses dos cidadãos, por meio do "construtivismo epistemológico", discussões coletivas e individuais não consentem, mas devem convergir, para que a democracia seja procedimento de comunicação para a tomada das decisões corretas.

\section{POLÍTICAS ESTRUTURANTES DE CONSOLIDAÇÃO DA RESPONSABILIDADE SOCIAL}

Associa-se a participação e o modelo de democracia deliberativa com a maneira como é implementada a responsabilidade social na empresa, já que sua importância já fora demonstrada, no que diz respeito ao exercício da cidadania.

Nesse âmbito, cabe analisar o alcance jurídico dessa responsabilidade social, bem como seus efeitos no ordenamento jurídico. Responsabilidade, no Direito Civil, é compreendida com a conotação patrimonial, na qual existe um prejuízo que deve ser sanado por meio do pagamento (NORONHA, 2010, p. 152), de modo a compor uma obrigação jurídica, o que conduz à compreensão da responsabilidade social das empresas como uma obrigação sem caráter vinculante, que busca agir em benefício da coletividade e ocasiona reflexos jurídicos tanto no contexto individual quanto de sociedade.

A ausência de vinculação decorre da falta de legislação específica reguladora do instituto, de modo que encontra base nos princípios constitucionais, inserindo-se "na dinâmica de proteção do princípio da dignidade da pessoa humana (...) compreendida entre as finalidades de função social do direito de propriedade empresarial e do contrato" (NEVES; OLIVEIRA, 2012, p. 84). Ainda, decorre de compromisso ético baseado no princípio da solidariedade e proteção dos direitos humanos (JONAS, 2012, p. 112), o que coaduna inclusive com as ideias do doutrinador Amartya Sen, quando fala sobre a pluralidade das identidades individuais que enseja a "diversidade plural muito unificadora, de uma forma que um sistema único de divisões predominantes não é" (SEN, 2010, p. 43). A superação do individualismo moderno, considera os interesses da coletividade e humaniza a cadeia produtiva, trazendo à tona uma consciência também moderna sobre as relações 
sociais. A ética associada à responsabilidade social configura, portanto, uma obrigação que auxilia na sistematização do ordenamento, ainda que não exista legislação específica.

Num segundo momento, a título de ilustração histórica para entender a maneira como foi consolidada essa concepção que se tem atualmente, é importante lembrar que a prática da responsabilidade social das empresas emergiu com o capitalismo no final do século XIX, ocasionada pelos efeitos econômicos e sociais da atividade, pois, ao mesmo tempo em que se produzia riqueza e gerava lucro, cresciam as desigualdades. Alguns casos internacionais paradigmáticos auxiliaram na construção da concepção atual, como o caso Dodge vs. Ford - no qual foi decidido que o lucro existia exclusivamente para beneficiar os acionistas e Smith Manufacturing vs. Barlow - decisão que permitiu doação mesmo contrariando o lucro (MORCELLI, 2016. p. 16).

Já no Brasil, a preocupação chegou um pouco mais tarde, em meados dos anos 60 , por meio da atuação de entidades religiosas preocupadas com a pobreza como a Associação de Dirigentes Cristãos de Empresas do Brasil, de modo que foi estimulada "consciência dos gestores em relação à responsabilidade social que levou as empresas a iniciarem envolvimento com as questões sociais" (MORCELLI, 2016, p. 17). O processo de evolução do conceito foi se desenvolvendo, consolidou o valor da ética empresarial e, após o período ditatorial, no final do século XX, a participação social nas empresas auxiliou na definição da responsabilidade social em si, culminando em atividades lançadas por Herbert de Souza (BERTONCINI; MUELLER, 2012, p. 468), Oded Grajew, dentre outros.

Assim, nesse percurso histórico, fica demonstrado que, da visão e atuação fordista de produção, desenvolveu-se o instituto de modo a conciliar a tecnologia com a vida digna (MORCELLI, 2016, p. 17), consolidando limites de exercício da atividade empresarial, o que ensejou da sociedade a exigência da ética da responsabilidade social das empresas. Conforme as referências históricas descritas, faz-se necessário abordar alguns exemplos modernos de políticas estruturantes que evidenciam a consolidação da responsabilidade social das empresas. 
Personalidade Acadêmica Homenageada:

Carlos Aurélio Mota de Souza (Universidade Ibirapuera - UNIB)

A esse respeito, tem-se o fenômeno da cooperativa empresarial ${ }^{4}$, situação advinda do processo de constituição da representação política do cooperativismo rural brasileiro, que constitui influente agente econômico pautado em uma forte gestão empresarial e na representação política do empresariado. Esse instituto visa a impactar sobre a institucionalização de sua ação política e estudar como seus dirigentes promovem tanto os interesses dos associados, como sociais, pois a cooperativa se assemelha à uma firma, mas assume o processo de representação e interesses, de modo a fomentar o processo de institucionalização da representação política dos grupos sociais.

Outra iniciativa empresarial para fomentar a mudança através do atendimento de demandas sociais é o "Minha Sampa", que busca fortalecer e aumentar o número de ações, campanhas e vitórias por uma São Paulo mais inclusiva, sustentável e democrática. Seu principal objetivo é a inclusão social, a fiscalização das decisões e consequente participação nelas e em outras ações criativas. Nesse ínterim, pode-se citar até mesmo a Lei Anticorrupção no 12.486/2013, que dispõe sobre a responsabilização administrativa e civil das pessoas jurídicas por atos contra a Administração Pública, de modo que considera tanto a obrigação da atividade ética, que não está regulada, como a responsabilidade objetiva do exercício probo. Outro exemplo reside no compliance e nas medidas ambientais responsáveis ou, até mesmo, na responsabilidade para com a erradicação do trabalho escravo, visto que devem ser desestimuladas e punidas práticas contra a proteção do trabalho humano.

No que concerne a esse papel da responsabilidade social da empresa, pretende-se a atuação conjunta com o Estado, em prol da coletividade, de modo que, atribuir deveres à empresa não significa esquivar o Estado das funções que Ihe são próprias, mas sim empenhar um trabalho em conjunto, já que a empresa possui a capacidade de "constatar uma sensível melhora nas condições econômico-financeiras das instituições que têm adotado medidas de caráter social. São alternativas viáveis e necessárias a esse novo contexto mundial" (ARNOLDI; MICHELAN, 2000, p. 161).

\footnotetext{
${ }^{4}$ Sobre o tema, Cf. COSTA, Paulo Roberto Neves; STOBERL, Paulo Roberto. Cooperativas e representação política empresarial no Brasil: o caso do cooperativismo rural no Paraná. Política \& Sociedade. Florianópolis, vol. 15, n. 32 - jan/abr 2016.

${ }^{5}$ Informação disponível em <https://www.minhasampa.org.br/\#block-5530> Acesso em 10 de março de 2018.
} 
Considerando que a sociedade cobra cada vez mais essa atuação, merece destaque $o$ alcance e relevância das ações voltadas para a responsabilidade social das empresas, seu compromisso para com fundamentos do ordenamento jurídico, bem como a evolução social. Deste modo, "é na originalidade das novas formas de experimentação institucional que podem estar os potenciais emancipatórios ainda presentes nas sociedades contemporâneas" (AVRITZER; SANTOS, 2002, p. 77).

\section{CONCLUSÃO}

A partir das constatações trazidas no decorrer desse trabalho, tem-se a clareza de que a responsabilidade social das empresas diante do desdobramento da economia de mercado e seus efeitos sociais adquire relevância na medida do seu compromisso com a evolução social, de modo que na realidade social brasileira, as ações de responsabilidade social das empresas estão justificadas quando comprometidas, de forma efetiva, com a redução de desigualdades em todos os níveis, ou seja, com uma nova prática, que veio resultar da mediação conceitual e normativa, convergente com a sustentabilidade do mundo e da vida de todas as pessoas.

Essa postura é exigida do empresariado, para promover o resgate da cidadania e o respeito à coletividade, fundamentada nos princípios constitucionais e valores sociais. As instituições que obtiverem sucesso na aplicação da responsabilidade social tem sua imagem valorizada, bem como a lealdade do consumidor e dos possíveis indivíduos que possam trabalhar lá, de modo que, com flexibilidade e adaptação, alcançam a longevidade. É por isso que, diante dessa mudança de paradigma, as empresas passaram a ter uma atuação mais incisiva na educação, lazer, cultura, meio ambiente, atuando de maneira a contribuir para a sustentabilidade, fiscalizando os efeitos de suas atividades e fomentando a evolução social.

As ações de responsabilidade social das empresas dependem do compromisso ético integrado ao desenvolvimento da vida em sociedade, de modo que 
Personalidade Acadêmica Homenageada:

Carlos Aurélio Mota de Souza (Universidade Ibirapuera - UNIB)

se pode concluir que a empresa pode e deve, de forma socialmente responsável, participar da vida democrática da sociedade na qual está inserida, fomentando a participação dos cidadãos e auxiliando o desenvolvimento social por meio dessa inserção. É nesse sentido que a empresa pode desenvolver a participação democrática, no presente trabalho focada no viés da democracia deliberativa, para se envolver no processo decisório.

Essa atuação é exercida com bases solidificadas nos preceitos da cidadania, em uma expressa manifestação do vínculo do indivíduo com o compromisso perante a sociedade, fomentada pela proteção dos direitos fundamentais pela participação nas estruturas da decisão - em seus diversos âmbitos, desde o administrativo até mesmo o político.

\section{REFERÊNCIAS}

ANDOLINA, Italo; VIGNERA, Giuseppe. O modelo Constitucional do Processo Civil Italiano. Torino: G. Giappichelli, 1990.

ARNOLDI, Paulo Roberto Colombo; MICHELAN, Taís Cristina de Camargo. Novos enfoques da função social da empresa numa economia globalizada. Revista de direito mercantil, industrial, econômico e financeiro, v. 39, n. 117, p. 157-162, jan./mar. 2000.

AVRITZER, Leonardo; SANTOS, Boaventura de Sousa. Introdução: para Ampliar o Cânone Democrático. In: SANTOS, Boaventura de Souza (Org.). Democratizar a Democracia: os caminhos da democracia participativa. Rio de Janeiro: Civilização Brasileira, 2002.

BESSA, Fabiane Lopes Bueno Netto. Responsabilidade social das empresas práticas sociais e regulação jurídica. Rio de Janeiro: Lúmen luris, 2006.

BERTONCINI, Mateus Eduardo Siqueira Nunes; MULLER, Ane Elize Deonara. O balanço social como instrumento jurídico da cidadania. Revista Jurídica Unicuritiba. Curitiba: Centro Universitário Curitiba, vol. n. 28, 2012, p. 465-485.

BOBBIO, Norberto. O Futuro da Democracia: uma Defesa das Regras do Jogo. 5. Ed. Rio de Janeiro: Paz e Terra, 1992.

BONAVIDES, Paulo. Ciência Política. 10. Ed. São Paulo: Malheiros, 2003. 
Personalidade Acadêmica Homenageada:

Carlos Aurélio Mota de Souza (Universidade Ibirapuera - UNIB)

BRASIL. Constituição da República Federativa do Brasil de 1988. Disponível em <http://www.planalto.gov.br/ccivil_03/constituicao/constituicao.htm> Acesso em 27 de fevereiro de 2018.

Lei 10.406 de 10 de janeiro de 2002. Disponível em <http://www.planalto.gov.br/CCivil_03/leis/2002/L10406.htm> Acesso em 27 de fevereiro de 2018.

CAETANO, Marcelo. Tendências do Direito Administrativo Europeu. Revista de Direito Público, São Paulo, n. 01, p. 25-39, jul./set. 1967.

CANDAU, Vera Maria. Sociedade, direitos humanos e cidadania: desafios para a educação no Brasil. In: SACAVINO, Susana; CANDAU, Vera Maria (Org.). Educação em direitos humanos. Petrópolis: DP et Alli Editora, 2008.

CANOTILHO, José Joaquim Gomes. Direito Constitucional. 5. Ed. 2. Reimp. Coimbra: Almedina, 1992.

CARDOSO, Jackson. A importância das organizações na sociedade. Disponível em: $\quad$ <http://www.administradores.com.br/artigos/negocios/a-importancia-dasorganizacoes -na -sociedade/69876/>. Acesso em 10 de março de 2018.

CARVALHO, Maria de Lourdes. A empresa contemporânea: sua função social em face das pessoas com deficiência. Belo Horizonte: Del Rey, 2012.

CAVALLAZZI FILHO, Tullo. O princípio da função social da propriedade e a empresa privada. Revista do Tribunal Regional Federal da $3^{\mathbf{a}}$ Região, v. 85, set-out. p. 5798. 2007.

CESAR, Monica de Jesus. "Empresa-cidadã": uma estratégia de hegemonia. São Paulo: Cortez, 2008.

COELHO, Fábio Ulhoa. Curso de Direito Empresarial: direito de empresa. São Paulo: Saraiva, 2012.

O Futuro do direito comercial. São Paulo: Saraiva, 2011.

COMPARATO, Fábio Konder. A Nova Cidadania. In: Direito Público: Estudos e Pareceres. São Paulo: Saraiva, 1996.

COSTA, Paulo Roberto Neves; STOBERL, Paulo Roberto. Cooperativas e representação política empresarial no Brasil: o caso do cooperativismo rural no Paraná. Política \& Sociedade. Florianópolis, vol. 15, n. 32 - jan/abr 2016.

COSTA, Philomeno Joaquim da. Autonomia do Direito Comercial. São Paulo: RT, 1956. 
Personalidade Acadêmica Homenageada:

Carlos Aurélio Mota de Souza (Universidade Ibirapuera - UNIB)

DARCANCHY, Mara. (coord.). Direito, inclusão e responsabilidade social. São Paulo: LTr, 2013.

ESPÍNDOLA, Ruy Samuel. Conceito de Princípios Constitucionais. São Paulo: Editora Revista dos Tribunais, 1999.

ETHOS, Instituto. Glossário. Disponível em: <https://www3.ethos.org.br/wpcontent/uploads/2013/09/Gloss\%C3\%A1 rioIndicadores-Ethos-V2013-09-022.pdf>. Acesso em: 01 de março de 2018.

FARIA, Cláudia Feres. Democracia deliberativa: Habermas, Cohen e Bohman. In Lua Nova, n. 50, 2000, p. 48. Disponível em: <http://www.scielo.br/scielo.php?script=sci_arttext\&pid=S010264452000000200004>. Acesso em 02 de março de 2018.

FERNANDES, Jean Carlos. Direito Empresarial Contemporâneo. Rio de Janeiro: Lumen Juris, 2015.

FERNANDES, Maria Elizabeth Moreira. Direito ao ambiente e propriedade privada: Aproximação ao estudo da estrutura e das consequências das 'leis-reserva' portadoras de vínculos ambientais. Coimbra: Coimbra Editora, 2001.

FONSECA, João Bosco Leopoldino da. Direito Econômico. Rio de Janeiro: Forense, 1995.

FERRARI, Regina Maria Macedo Nery. Participação Democrática: Audiências Públicas. In: CUNHA, Sérgio Sérvulo; GRAU, Eros Roberto (orgs.) Estudos de Direito Constitucional em Homenagem a José Afonso da Silva. São Paulo: Malheiros, 2003.

FERREIRA FILHO, Manoel Gonçalves. Comentários à Constituição Brasileira de 1988. 3. Ed. São Paulo: Saraiva, 2000. v. 1.

GRAU, Eros Roberto. A ordem econômica na Constituição de 1988. 10. ed. São Paulo: Malheiros, 2005.

Elementos de direito econômico. São Paulo: Revista dos tribunais, 1981.

JONAS, Hans. O princípio responsabilidade: ensaio de uma ética para a civilização tecnológica. Rio de Janeiro: Contraponto: PUC-Rio, 2006.

LOPES, Alex Luís Luengo. A empresa privada à luz da ordem econômica constitucional brasileira de 1988: papel, função e responsabilidade social. Dissertação - Mestrado em Direito da Universidade de Marília, Marília, 20 de outubro de 2006. 
Personalidade Acadêmica Homenageada:

Carlos Aurélio Mota de Souza (Universidade Ibirapuera - UNIB)

MACHADO, Francisco Mata. O Estado na democracia deliberativa: as raízes de uma antinomia. Lua Nova: São Paulo, 95: 225-257, 2015. Disponível em: $<$ http://www.scielo.br/scielo.php?pid=S010264452015000200225\&script=sci_abstrac t\&tlng=PT>. Acesso em 02 de março de 2018.

MARTINS, V. A função promocional do direito tributário na extrafiscalidade por estímulos: o direito como indutor de uma cidadania ativa e participante. Dissertação de Mestrado em Direito. Universidade de Santa Cruz do Sul, Brasil, 2009.

MEDAUAR, Odete. Administração Pública ainda sem Democracia. Problemas Brasileiros, São Paulo, a. 23, n. 256, p. 37-53, mar./abr. 1986.

MELLO, Celso Antônio Bandeira de. Curso de Direito Administrativo. 30. ed. São Paulo: Malheiros, 2013.

MORCELLI, Aier Tadeu; ÁVILA, Lucas Veiga. Responsabilidade social. Santa Maria: Universidade Federal de Santa Maria, Colégio Politécnico: Rede e-Tec Brasil, 2016.

MOREIRA NETO, Diogo Figueiredo. Direito da Participação Política. Renovar: Rio de Janeiro, 1992.

NETO, L. Teoria funcionalista e função promocional do direito. Revista Jus Navigandi. Teresina, Ano 16, 2011.

NEVES, Ligia Alves; OLIVEIRA, Francisco Cardozo. O paradigma da justiça social como referencial teórico da responsabilidade social empresarial. Rio de Janeiro: Editora Clássica, 2012.

NORONHA, Fernando. Direito das obrigações. São Paulo: Editora Saraiva, 2010.

OLIVEIRA, Gustavo Henrique Justino de. As Audiências Públicas e o Processo Administrativo Brasileiro. Revista de Direito Administrativo, Rio de Janeiro, n. 209, p. 153-167, jul./set. 1997.

OLIVEIRA, Lourival José de. A função social da empresa privada e a desagregação causada pelo novo modo de produção. Diritto \& Diritti, v. 1, p. 2-14, 2008.

PERAZZO, Alberto Augusto. Ética e responsabilidade social: uma questão de estratégia empresarial. In: WHITAKER, Maria do Carmo (Coord.). Ética na vida das empresas: depoimentos e experiências. São Paulo: DVS, 2007.

RIBEIRO, Fernando José Armando. O princípio da função social da propriedade e a compreensão constitucionalmente adequada do conceito de propriedade. Revista da Faculdade de Direito Milton Campos, Belo Horizonte, Del Rey, v. 7, 2000. 
Personalidade Acadêmica Homenageada:

Carlos Aurélio Mota de Souza (Universidade Ibirapuera - UNIB)

ROCHA FILHO, José Maria. Curso de Direito Comercial: parte geral. Atualizada conforme o novo Código Civil. Belo Horizonte: Del Rey, 2004.

ROMAN, Artur. Responsabilidade Social das Empresas: um pouco de história e algumas reflexões. Revista FAE Business. Número 9. Setembro de 2004.

ROSENVALD, Nelson; FARIAS, Cristiano Chaves de. Curso de Direito Civil: parte geral e LINDB. Salvador: Jus Podivm, 2012.

SAINSAULIEU, Renaud; KIRSCHNER, Ana Maria. Sociologia da empresa: organização, poder, cultura e desenvolvimento no Brasil. Rio de Janeiro: DP\&A, 2006.

SANTIAGO, García Echevarría. Introducción a la economia de la empresa. Madrid: Díaz de Santos, 1994.

SARMENTO, Daniel. Ubiquidade Constitucional: Os Dois Lados da Moeda. In NETO, Cláudio Pereira de Souza. A Constitucionalização do Direito: Fundamentos Teóricos e Aplicações Específicas. Coordenadores. Lumen Júris. Rio de Janeiro: 2007.

SERRA, C. Responsabilidade social das empresas através do direito (e o direito à luz da responsabilidade social das empresas). Responsabilidade Social - Uma visão Ibero-Americana. Coimbra: Livraria Almedina, 2011.

SILVA, José Afonso da. Curso de Direito Constitucional positivo. 19. ed. São Paulo: Malheiros, 2001.

SILVA, Marcos Alves; KNOERR, Viviane Coelho de Séllos. Responsabilidade social da empresa e subcidadania pautas para uma reflexão de índole constitucional. Revista Jurídica - Unicuritiba. Curitiba: Centro Universitário Curitiba, 2013, vol. 2, ก. -31 , p. $435-453$.

SOUZA, Carlos Aurélio Mota de. (org.). Responsabilidade social das empresas. São Paulo: Juarez de Oliveira, 2007.

SOUZA NETO, Claudio Pereira de. Teoria constitucional e democracia Deliberativa. Editora Renovar: Rio de Janeiro, 2006.

TEUBNER, G. Juridificação - noções, características, limites, soluções. Revista de Direito e Economia. Coimbra, Ano XIV, 1988.

VIEIRA, Liszt. Cidadania e Globalização. 6. Ed. Rio de Janeiro: Record, 2002.

ZOLO, Danilo. Teoria e crítica do estado de direito. In: COSTA, Pietro e ZOLO, Danilo (ORGS). 0 estado de directo - história, teoria e crítica. Martins Fontes. São Paulo: 2006. 